Société d'histoire de la révolution de 1848 et des

révolutions du XIXe siècle

$19 \mid 1999$

Aspects de la production culturelle au XIXe siècle

\title{
Fidélité républicaine et monde rural
}

\section{OpenEdition \\ Journals}

Édition électronique

URL : http://journals.openedition.org/rh19/196

DOI : $10.4000 /$ rh19.196

ISSN : $1777-5329$

\section{Éditeur}

La Société de 1848

\section{Édition imprimée}

Date de publication : 1 décembre 1999

Pagination : 167

ISSN : 1265-1354

Référence électronique

"Fidélité républicaine et monde rural », Revue d'histoire du XIXe siècle [En ligne], 19 | 1999, mis en ligne le 26 août 2008, consulté le 15 septembre 2020. URL : http://journals.openedition.org/rh19/196

Ce document a été généré automatiquement le 15 septembre 2020.

Tous droits réservés 
Fidélité républicaine et monde rural 
1 S. Aprile, J.-F. Chanet, J.-E. Iung et B. Vandeplas ont organisé avec la Société des lettres, sciences et arts la " haute Auvergne " un intéressant colloque qui s'est tenu à Aurillac les 27-28 août 1999. Autour de la Seconde République et de ses campagnes étaient convoqués plusieurs spécialistes qui avaient accepté de s'insérer dans l'une des trois sessions proposées. La Montagne, ou des Montagnards?: " Aux origines d'une tradition rouge: les campagnes du Cher sous la Seconde République" (M. Pigenet); "Les républicains en Corrèze (1848-1851) " (C. Latta) ; "L'implantation démocrate-socialiste dans les campagnes bourbonnaises: l'exemple du canton du Donjon (Allier) sous la Seconde République" (M. Bernard); " Militants montagnards dans les campagnes bourguignonnes " (P. Lévêque) ; " Le Valois rouge " (J.-P. Besse). Acculturation et fidélités : "Les campagnes cantaliennes et la Seconde République du printemps 1848 aux législatives de mai 1849. Adhésion sincère ou formalisme politique?" (J.-P. Serre et B. Vandeplas); " La fête de la promulgation de la constitution de 1848 dans l'Allier, le Cantal, la Haute-Loire et le Puy-de-Dôme " (J. Lalouette); " Républicanisme rural et riposte au coup d'État de décembre 1851. Enquête sur la diversité des comportements républicains " (R. Huard) ; " Une acculturation politique à droite? Les conservateurs et l'apprentissage du suffrage universel dans le département de l'Ain " (P. Boutry); " Le poids de la culture républicaine rurale de 1848-1851 dans la géographie politique d'André Siegfried " (G. Pécout). Médiations : " 1848-1849 dans le Cantal. Un prêtre entré en politique: l'abbé Thouzery" (C. Estève); "Un notable rural et l'engagement républicain : l'exemple de Frédéric Dupuy-Grandval " (C. Grimmer); " Félix Esquirou de Parieu ou la fidélité du rallié " (J.-F. Chanet) ; " Au temps des sociétés secrètes : le rôle des rumeurs en Ardèche sous la Seconde République " (J. Merriman); "Coupables d'excitation: intermédiaires et médiateurs des luttes républicaines dans les campagnes " (S. Aprile). Les conclusions du colloque ont été tirées par J.-L. Mayaud, qui, se félicitant de la richesse des communications, a insisté sur la nécessité d'une approche fine, nominative et longitudinale, de la "République au village ". La Revue d'histoire du XIXe siècle rendra compte des actes de ce colloque dont la publication est annoncée.

Renseignements: Société la haute Auvergne, 1 rue du 139e RI, 15012 Aurillac cedex, Tél. : 0471483338. 